PREPARED FOR THE U.S. DEPARTMENT OF ENERGY, UNDER CONTRACT DE-AC02-76CH03073

PPPL-3607

PPPL-3607

UC-70

Application of Stark Tuned Laser

for Interferometry and Polarimetry in Plasmas

by

H.K. Park, K.C. Lee, B. Deng, C.W. Domier, M. Johnson, B. Nathan, and N.C. Luhmann, Jr.

September 2001

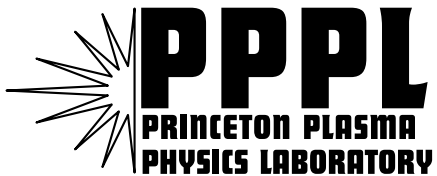



PRINCETON PLASMA PHYSICS LABORATORY PRINCETON UNIVERSITY, PRINCETON, NEW JERSEY 


\section{PPPL Reports Disclaimer}

This report was prepared as an account of work sponsored by an agency of the United States Government. Neither the United States Government nor any agency thereof, nor any of their employees, makes any warranty, express or implied, or assumes any legal liability or responsibility for the accuracy, completeness, or usefulness of any information, apparatus, product, or process disclosed, or represents that its use would not infringe privately owned rights. Reference herein to any specific commercial product, process, or service by trade name, trademark, manufacturer, or otherwise, does not necessarily constitute or imply its endorsement, recommendation, or favoring by the United States Government or any agency thereof. The views and opinions of authors expressed herein do not necessarily state or reflect those of the United States Government or any agency thereof.

\section{Availability}

This report is posted on the U.S. Department of Energy's Princeton Plasma Physics Laboratory Publications and Reports web site in Calendar Year 2001. The home page for PPPL Reports and Publications is: http://www.pppl.gov/pub_report/

DOE and DOE Contractors can obtain copies of this report from:

U.S. Department of Energy

Office of Scientific and Technical Information

DOE Technical Information Services (DTIS)

P.O. Box 62

Oak Ridge, TN 37831

Telephone: (865) 576-8401

Fax: (865) 576-5728

Email: reports@adonis.osti.gov

This report is available to the general public from:

National Technical Information Service

U.S. Department of Commerce

5285 Port Royal Road

Springfield, VA 22161

Telephone: 1-800-553-6847 or

(703) 605-6000

Fax: (703) 321-8547

Internet: http://www.ntis.gov/ordering.htm 


\title{
APPLICATION OF STARK TUNED LASER FOR INTERFEROMETRY AND POLARIMETRY IN PLASMAS
}

\author{
H. K. PARK \\ Princeton Plasma Physics Laboratory, P.O. Box 451, Princeton, New Jersey 08543 \\ K.C. LEE, B. DENG, C. W. DOMIER, M. JOHSNSON, B. NATHAN, N. C. LUHMANN, \\ JR. \\ Department of Applied Science, University of California at Davis, California 95616
}

\begin{abstract}
A Stark-tuned optically pumped far-infrared $\mathrm{CH}_{3} \mathrm{OH}$ laser[1] at $119 \mu \mathrm{m}$ has been successfully applied in the Far Infrared Tangential Interferometer/Polarimeter (FIReTIP) system [2] for the National Spherical Torus Experiment (NSTX). The system will provide temporally and radially resolved 2-D electron density profile $\left[\mathrm{n}_{\mathrm{e}}(\mathrm{r}, \mathrm{t})\right]$ and toroidal field profile $\left[\mathrm{B}_{\mathrm{T}}(\mathrm{r}, \mathrm{t})\right]$ data. In the 2001 campaign, a single channel interferometer system has been operated and tested for the Faraday rotation measurement. A plan for improvement and upgrading of the FIReTIP is discussed.
\end{abstract}

\section{Introduction}

In general interferometry systems for large plasma devices, the heterodyne far-infrared laser system $\left(10 \mu \mathrm{m}<\lambda_{\mathrm{o}}<1000 \mu \mathrm{m}\right)$ has been extremely popular. There are two well known techniques in modulating the frequency; the frequency shift has been introduced by either by a mechanically rotating grating or two laser systems with a constant cavity difference frequency tune. In both cases, the maximum achievable frequency modulation is limited by the speed of the rotating grating $(<100 \mathrm{kHz})$ and the intrinsic narrow gain bandwidth available in these molecular FIR lasers $(<2 \mathrm{MHz})$, respectively.

In the TFTR interferometer system based on two identical lasers operating at $119 \mu \mathrm{m}$, two problems arose from the low modulation frequency $(\sim 1 \mathrm{MHz})$. One was the loss of fringe counts when the change of density exceeded the bandwidth of the counting system that is limited by the modulation frequency itself. Such a rapid change in density occurred during a sudden disruption or when solid pellets were injected. This shortcoming can certainly be improved upon if the modulation frequency can be significantly increased. The main reason is that the basic principle of interferometry is based on measuring the changes of phase between two sinusoidal beat frequencies $\left[\cos \left(\omega_{\text {if }} t\right)\right.$ and $\left.\cos \left(\omega_{\text {if }} t+\phi(t)\right)\right]$. Here, $\omega_{\text {if }}$ is the modulation frequency and $\phi(t)$ is proportional to the plasma density along the direction of the probe beam. If the rate of change of the plasma density is large so that $\mathrm{d} \phi(\mathrm{t}) / \mathrm{dt}$ is larger than $\omega_{\text {if }}$, it is impossible to measure the density. To ensure that the measurement can be made at all times, the following condition must be satisfied; 


$$
\frac{d \phi(t)}{d t} \ll<\omega_{i f}
$$

The other difficulty is a practical problem associated with the thermal expansion of laser cavities that will change the operating modulation frequency. There are number of techniques available to lock the operating frequency. In principle, at a higher modulation frequency, there is more room to tolerate the range of variation whether the system employs a specific technique or not. A Stark-tuned FIR laser was suggested by Mansfield[1] for this application, since the modulation frequency can be significantly increased without loss of laser power.

The primary goal of this paper is to demonstrate an application of the Stark-tuned FIR laser system in the Interferometry/Polarimetry system on NSTX that was intended to measure the toroidal magnetic field. Simultaneously, temporally resolved (up to $\sim 500 \mathrm{kHz}$ ) 2D density profile information will be available as well. Since the laser wavelength of $119 \mu \mathrm{m}$ is an ideal wavelength for NSTX parameters, the system design is based on three FIR lasers including a Stark-tuned laser operating at $119 \mu \mathrm{m}$ together with the accumulated wisdom from the TFTR multichannel infrared interferometer [MIRI] system [3]. Successful demonstration of the interferometry system and preliminary test results from Faraday rotation warrant an ambitious upgrading plan for the system.

\section{Principles}

In an interferometry/polarimetry system, the O-mode polarized radiation in the magnetically confined plasma undergoes a phase shift given by

$$
\phi(x)=2.8 \times 10^{-15} \lambda \int_{0}^{x} n\left(x^{\prime}\right) d x^{\prime}
$$

In the presence of a parallel magnetic field component, $B \mathrm{~T}$, the polarization of the wave is Faraday rotated through an angle

$$
\Psi(x)=2.6 \times 10^{-13} \lambda^{2} \int_{0}^{x} n\left(x^{\prime}\right) B_{\mathrm{T}}\left(x^{\prime}\right) d x^{\prime}
$$

With a sufficient number of chords spanning the plasma, interferometry data can be inverted to yield the temporally and radially resolved plasma density $\mathrm{n}_{\mathrm{e}}(r, t)$. Polarimetry data can be subsequently inverted to yield the time dependent parallel magnetic field $\mathrm{B}_{\mathrm{T}^{(r, t)}}$.

The FIReTIP system design for NSTX is based on a wavelength of $119 \mu \mathrm{m}$ that is ideal for NSTX plasma parameters. At this wavelength, the expected signal to noise ratio for interferometry and polarimetry is excellent. The interferometer system will have $\sim 10$ fringes shift and the polarimetry system will have a Faraday rotation of $\sim 10$ degrees while the refraction of the beam is at a minimum (less than $\sim 0.5 \mathrm{~mm}$ ) as shown in Fig. 3 in Ref. 2 . Due to an access limitation, the present system consists of seven beam lines that enter at three separate toroidal locations at Bay $\mathrm{K}$ on NSTX as shown schematically in Fig. 1. Each beam traverses a different chord along the horizontal midplane of the device, reflects from a suitably placed corner cube retro-reflector, and traverses back through the plasma to return to a common point for detection.

There has been significant progress in Faraday rotation measurement. The technique we are implementing on this system is modulation of polarization of the probe beam. A major limitation of the rotating half-wave plate used in the MTX measurement is the limited modulation rate $(<10$ $\mathrm{kHz}$ ) that can be created by the mechanically rotating plate. This limitation can be removed by 
replacing the rotating plate by an additional far-infrared (FIR) laser. In this approach pioneered by Rommers and Howard on RTP [4], the rotating elliptically polarized wave is formed by injecting two co-aligned counter-rotating circularly polarized laser beams into the plasma. This scheme is illustrated in Fig. 4 of Ref. 2. The beams, generated by separate FIR lasers with frequencies $\omega_{1}$ and $\omega_{2}$, are slightly offset to allow the use of heterodyne detection methods.

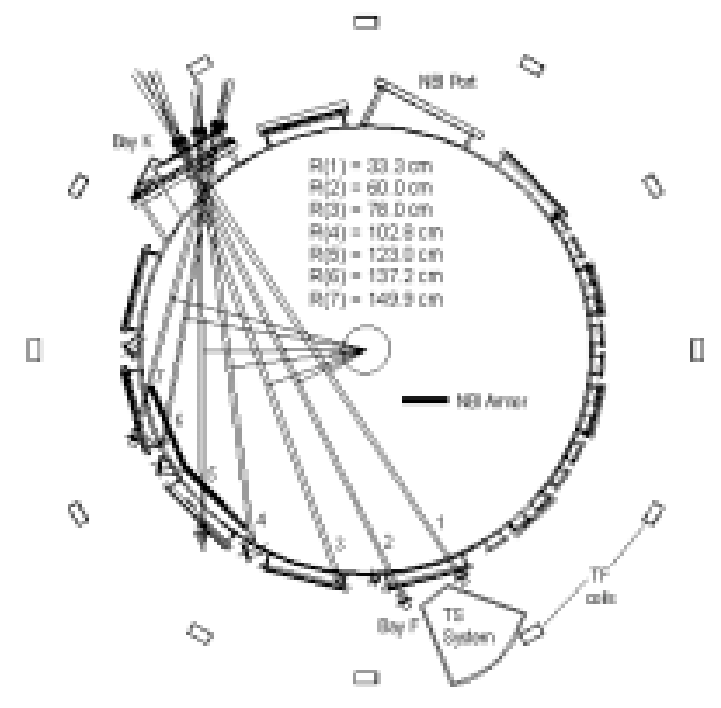

Fig. 1. Seven channel FIReTIP system will have fan view of beam lines. Three entrance windows and tangencies of each beam lines are provided

The FIReTIP system utilizes an approach similar to that used on RTP. In this case, however, the FIR lasers operate at $119 \mu \mathrm{m}$ with a difference frequency $\omega_{1}-\omega_{\mathrm{LO}}=4.0 \pm 1.0 \mathrm{MHz}$ and $\omega_{2}-\omega_{\mathrm{LO}}=6.0 \pm 1.0 \mathrm{MHz}$. The LO frequency shift of $5 \mathrm{MHz}$ is obtained using the Stark tuned FIR laser in addition to two FIR lasers operating with a frequency difference of $2 \mathrm{MHz}$. This generates interferometer and polarimeter signals at 6.0 and 4.0 MHz. Phase lock loop circuits and a tracking system [5] are utilized to upconvert the laser signals to $24.0 \mathrm{MHz}$, whereupon flip-flop based fringe counter circuits measure the interferometer signal(s), and a quadrature phase comparator system makes Faraday rotation measurements with high temporal resolution. Note that only a single detector is required for each chord in the tangential interferometer system.

\section{Laser System}

The laser system consists of three FIR lasers which are equally pumped by the grating-tuned $\mathrm{CO} 2$ laser delivers $\sim 70 \mathrm{~W}$. The conventional two FIR lasers are described in Ref. 3. The design of the Stark-tuned FIR resonator is quite similar to the one described in Ref. 4. The resonator consists of a rectangular Pyrex tube with inside dimension of $22 \times 9.5 \mathrm{~mm}$. The two large inside faces of the rectangular tube are coated by evaporating a conducting film of Al. The rectangular tube is surrounded by a double cylindrical water jacket so that the entire structure is water cooled and free from electrical breakdown. The input coupler consists of a flat Au-coated copper mirror with a centered 4-mm input coupling hole. A hybrid metal-dielectric mirror with a 6-mm Si aperture is employed as the output coupler which is commonly used in most high power FIR laser systems. The output of the two conventional FIR lasers was $\sim 40 \mathrm{~mW}$ and that of the Stark laser was $\sim 20$ $\mathrm{mW}$. The applied voltage was $\sim 400 \mathrm{~V}$ to avoid an occasional break down at the operating pressure 
( $\sim 50 \mathrm{mT}$ at the pump side of the gas system) which was lower than the test set up used in Ref. 1. The spectral performance of the Stark-tuned laser was very much consistent with the results in Ref. 1. An example of the beat frequencies are shown in Fig. 2. The choice of this frequency was to optimize the output power while minimizing operational risks including electrical breakdown.

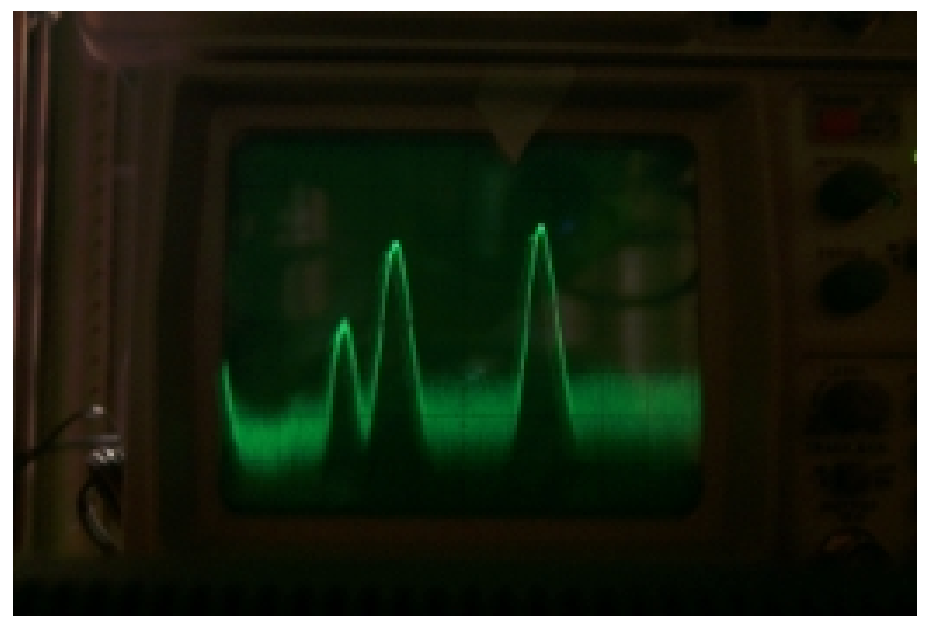

Fig. 2. The actual operating frequency of the interferometer system is illustrated. (right hand side is $\sim 7 \mathrm{MHz}$ which is the edge of upper bound and middle one is $\sim 4 \mathrm{MHz}$. The beating frequency between the non-Stark lasers is $\sim 3 \mathrm{MHz}$.

\section{Optical system configuration}

The beam propagation is largely divided into three sections. First and second sections consist of two focusing mirrors that collimate the laser beams (effective beam waist of $\sim 0.4 \mathrm{~cm}$ ) to an appropriate size (beam waist of $\sim 2.2 \mathrm{~cm}$ ) so that splitting and detection can be arranged with collimated beams. The final section is propagation through the plasma and retro-reflectors.

The partial layout of optical components is shown for the first three channels in Fig.3. Electroformed $\mathrm{Cu}$ meshes will be utilized as beam splitters and partial reflectors. The characteristics of these metal meshes have been studied in detail [6] and are known to distort beam polarizations for non-normal incidence. In order to split the probing beam into seven parts which will be directed to retro-reflectors with a minimum polarization change, the reflection angles are maintained at 10 degree. Splitting the LO beam into seven parts can be achieved with these beam splitters too. They will be directed to each of the Schottky diode corner cube detectors and polarizing grids with which the interferometer and polarimeter signals are to be measured. 


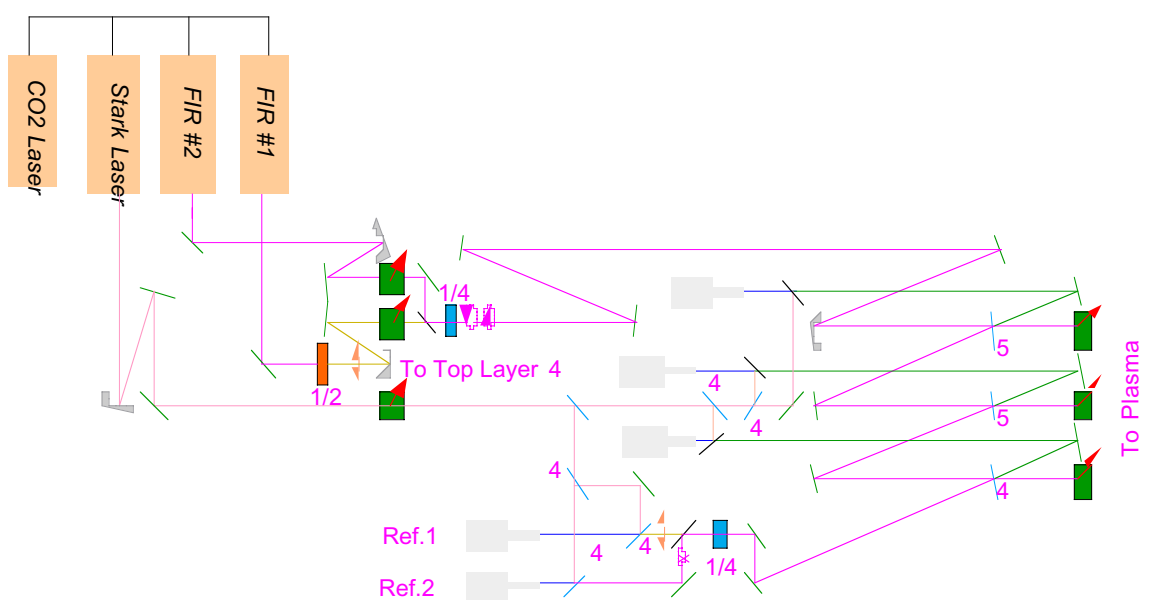

Fig.3. Optical arrangement for the first three channels. FIR \# 1 and \#2 are combined by polarizer and propagates as two different circular polarizations. Stark laser is used as local oscillator only. 4 and 5 stands for metal mesh with 400 lpi and 500 lpi, repectivley.

Each beam will be guided to the mid-plane where quartz windows are located at Bay K of NSTX as shown in Fig. 4. The thickness of crystal quartz is adjusted so that the reflection at the surface is minimum for this wavelength. For channels \# 1 and \#2, two exit windows are located at Bay $\mathrm{F}$ where retro-reflectors are mounted on the base plate of the Thomson scattering detection system.

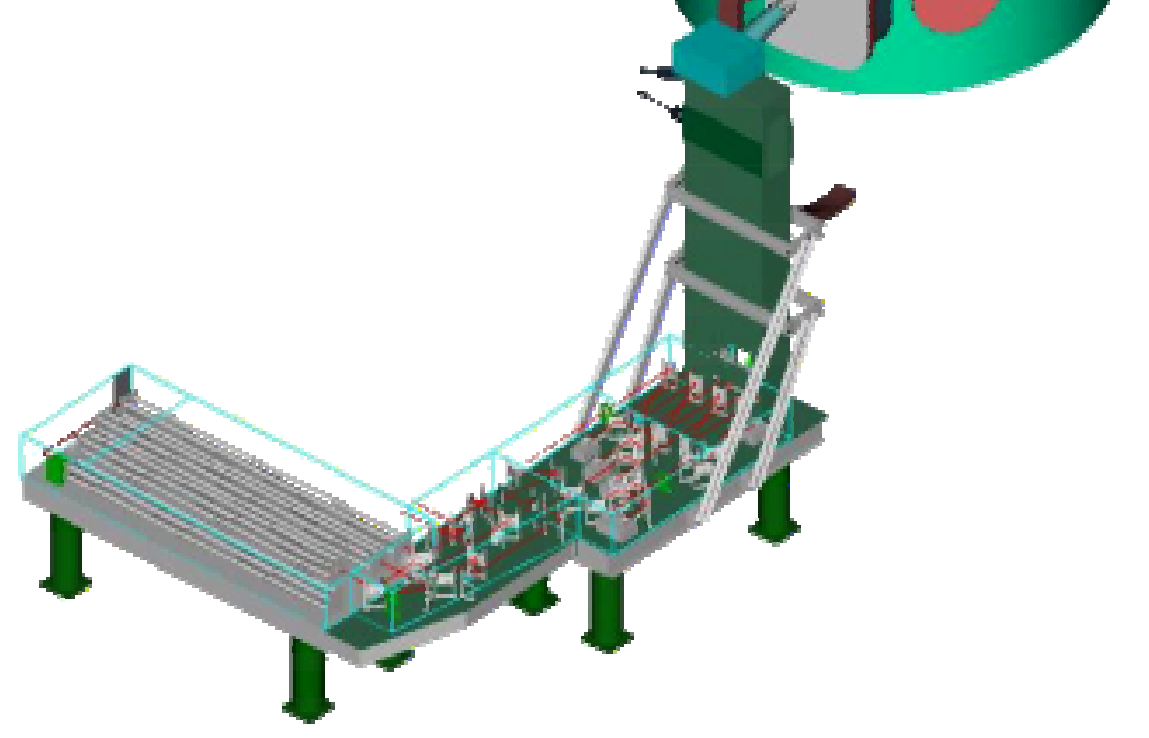

Fig. 4. 3-D CAD design of FIReTIP system. Beams from the optical table are entering the window at Bay $\mathrm{K}$ through optical tower. 


\section{Preliminary experimental results and upgrade plan}

During the 2001 campaign, the goal was to demonstrate a single channel interferometer and the feasibility of Faraday rotation measurement. During this commissioning period, two major trouble-shootings were performed. First, the laser operation was hampered by magnetic influence which mainly came from $\mathrm{OH}$ and PF systems. Note that the laser system was hardened in the TFTR magnetic environment. This implies that the magnetic impact on the laser system has been much worse compared to that of the TFTR operation. The reason was that the change of $\mathrm{OH}$ flux and PF field was much stronger due to the short pulse length. Second, vibrations transmitted through the floor influenced the optical components to oscillate at their resonance frequencies. Typical resonance frequencies were $\sim 30 \mathrm{~Hz}$ and $50 \mathrm{~Hz}$. The optical tables are now isolated with vibration dampening materials to suppress these oscillations.

Since the Bay K, where a temporary entrance window was installed, is scheduled to be redesigned, one channel was aligned at the tangency of $\sim 66 \mathrm{~cm}$ [close to channel \#2]. In this campaign, a single channel operation was successful and test results of Faraday rotation measurements were acquired before the August shut down. Sample density data [second trace] and quadrature signals from the Faraday rotation measurements [last two traces] are shown in Fig. 5 together with other waveforms of the discharge. During this shut down time we intend to redesign the optical tower so that two more channels will be added including the very edge channels before completion of the full system. Also, small oscillations in density traces which originated from the floor vibration will be isolated by activating an air cushion system on the optical tables for the next run time.
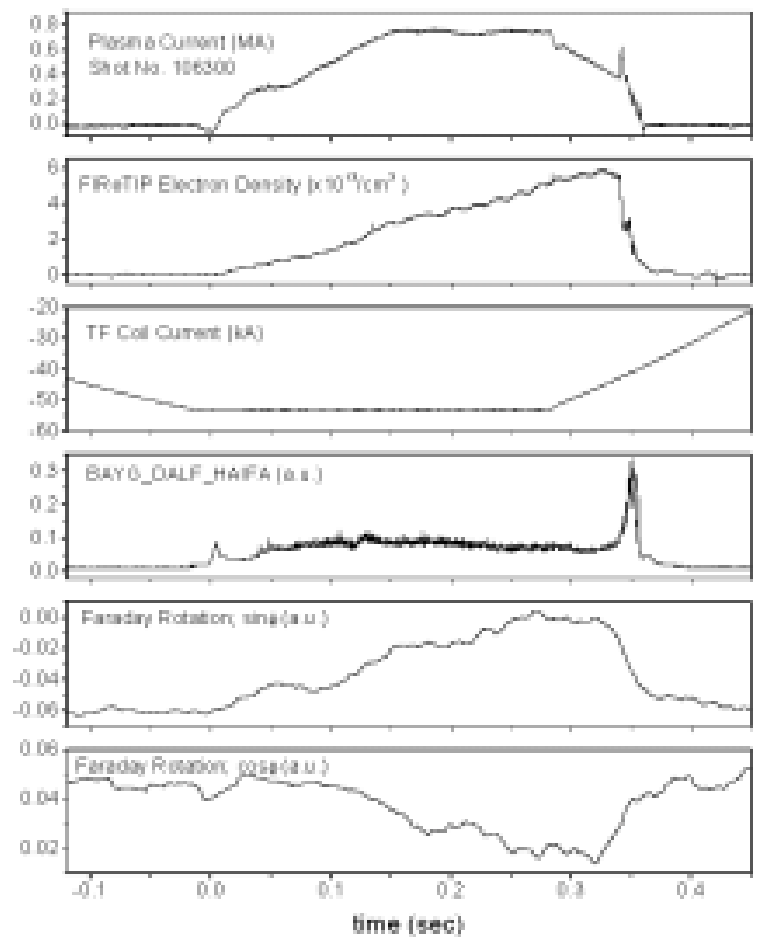

Fig. 5. A measured line average density (second trace) and quadrature signals (last two traces) from Faraday rotation measurement with other waveforms. 


\section{Summary}

We have successfully demonstrated the advantage of Stark-tuned laser system on NSTX interferometry/polarimetry system. This paper presents a description of Interferometer/polarimeter system emphasizing the usage of the Stark-tuned laser system. The successful operation of a single channel system warrants upgrading the system up to the full design specification.

\section{Acknowledgement}

This work is supported by the U.S. Department of Energy under contract Nos. DE-AC02-76CH0-3073, DE-FG03-99ER54531 and DE-FG03-95ER54295.

\section{References}

[1] D.K. Mansfield P.A. Krug, M. Vocaturo, L. Guttadora, M. Rockmore, and K. Micai, Applied Optics, 31, pp. 5029-5033, (1992)

[2] H. Park, C.W. Domier, W.R. Geck and N.C. Luhmann, Jr., Rev. Sci. Instrum., 70, pp. 710713, (1999).

[3] D.K. Mansfield, H.K. Park, L.C. Johnson, H. Anderson, S. Foote, B. Clifton and C.H. Ma, "Multichannel Far-Infrared Laser Interferometer for Electron Density Measurements on the Tokamak Fusion Test Reactor," Applied Optics 26, pp. 4469-4474 (1987).

[4] J.H. Rommers, A.J.H. Donné, F.A. Karelse and J. Howard, "The Multichannel Triple-Laser Interferometer/Polarimeter System at RTP," Review of Scientific Instruments 68, pp. 12171226 (1997).

[5] C.W. Domier, W.A. Peebles, and N.C. Luhmann, Jr., "Millimeter-Wave Interferometer for Measuring Plasma Electron Density," Review of Scientific Instruments 59, pp. 1588-1590 (1988).

[6] Y.S. Hwang and H.K. Park, "Polarization Characteristics of Wire Mesh at $119 \mu \mathrm{m}$," Applied Optics 28, pp. 4999-5001 (1989). 


\section{External Distribution}

Plasma Research Laboratory, Australian National University, Australia

Professor I.R. J ones, Flinders University, Australia

Professor J oão Canalle, Instituto de Fisica DEQ/IF - UERJ , Brazil

Mr. Gerson O. Ludwig, Instituto Nacional de Pesquisas, Brazil

Dr. P.H. Sakanaka, Instituto Fisica, Brazil

The Librarian, Culham Laboratory, England

Library, R61, Rutherford Appleton Laboratory, England

Mrs. S.A. Hutchinson, JET Library, England

Professor M.N. Bussac, Ecole Polytechnique, France

Librarian, Max-Planck-Institut für Plasmaphysik, Germany

J olan Moldvai, Reports Library, MTA KFKI-ATKI, Hungary

Dr. P. Kaw, Institute for Plasma Research, India

Ms. P.J . Pathak, Librarian, Insitute for Plasma Research, India

Ms. Clelia De Palo, Associazione EURATOM-ENEA, I taly

Dr. G. Grosso, Instituto di Fisica del Plasma, Italy

Librarian, Naka Fusion Research Establishment, J AERI, J apan

Library, Plasma Physics Laboratory, Kyoto University, J apan

Research Information Center, National Institute for Fusion Science, J apan

Dr. O. Mitarai, Kyushu Tokai University, J apan

Library, Academia Sinica, Institute of Plasma Physics, People's Republic of China

Shih-Tung Tsai, Institute of Physics, Chinese Academy of Sciences, People's Republic of China

Dr. S. Mirnov, TRINITI, Troitsk, Russian Federation, Russia

Dr. V.S. Strelkov, Kurchatov Institute, Russian Federation, Russia

Professor Peter Lukac, Katedra Fyziky Plazmy MFF UK, Mlynska dolina F-2, Komenskeho Univerzita, SK-842 15 Bratislava, Slovakia

Dr. G.S. Lee, Korea Basic Science Institute, South Korea

Mr. Dennis Bruggink, Fusion Library, University of Wisconsin, USA

Institute for Plasma Research, University of Maryland, USA

Librarian, Fusion Energy Division, Oak Ridge National Laboratory, USA

Librarian, Institute of Fusion Studies, University of Texas, USA

Librarian, Magnetic Fusion Program, Lawrence Livermore National Laboratory, USA

Library, General Atomics, USA

Plasma Physics Group, Fusion Energy Research Program, University of California at San Diego, USA

Plasma Physics Library, Columbia University, USA

Alkesh Punjabi, Center for Fusion Research and Training, Hampton University, USA

Dr. W.M. Stacey, Fusion Research Center, Georgia Institute of Technology, USA

Dr. J ohn Willis, U.S. Department of Energy, Office of Fusion Energy Sciences, USA

Mr. Paul H. Wright, Indianapolis, Indiana, USA 
The Princeton Plasma Physics Laboratory is operated by Princeton University under contract with the U.S. Department of Energy.

\author{
Information Services \\ Princeton Plasma Physics Laboratory \\ P.O. Box 451 \\ Princeton, NJ 08543
}

Phone: 609-243-2750

Fax: 609-243-2751

e-mail: pppl_info@pppl.gov

Internet Address: http://www.pppl.gov 